\title{
Effects of electroacupuncture on stress and anxiety-related responses in rats
}

\author{
RICARDO M. BASSETTO, TATIANA WSCIEKLICA, KATHLEIN C.P. POUZA, DANIELA \\ ORTOLANI, MILENA B. VIANA, ISABEL C. CESPEDES and REGINA C. SPADARI
}

Departamento de Biociências, Instituto Saúde e Sociedade, Campus Baixada Santista, Universidade Federal de São Paulo, Rua Silva Jardim, 136, 11015-020 Santos, SP, Brazil

Manuscript received on August 11, 2016; accepted for publication on November 21, 2016

\begin{abstract}
The aim of this work was to investigate if eletroacupuncture at PC6 would modulate the stress-induced anxiety-like behavior and the level of activation of several brain areas. Rats were distributed in groups: control; submitted to immobilization; submitted to immobilization and eletroacupuncture at PC6 or at the tail. Immobilization increased grooming and decreased stretched attend postures and the time spent in the open arms of the ele-vated plus-maze. Eletroacupuncture at PC6 or tail canceled the effect of immobilization on grooming and attenuated the stretched attend posture. Immobilization increased Fosimmunoreactivity in the prefrontal cortex, medial and central amygdala, paraventricular and dorsomedial nuclei of the hypothalamus, lateral hypothalamus, dentate gyrus, CA1, CA2 and CA3 hippocampal areas. The activation of paraventricular, dorsomedial nuclei and prefrontal cortex by immobilization was canceled by electroacupuncture at PC6 and attenuated by electroacupuncture in the tail. The activation of the other areas was canceled by electroacupuncture in PC6 or the tail. It is concluded that immobilization induced anxiety-like behavior that was moderately attenuated by eletroacupuncture with difference between the stimulation in PC6 or the rat tail. Eletroacupuncture showed specificity concerning to the attenuation of the effects of immobilization in the CNS areas related to the stress response, anxiety and cardiovascular system.
\end{abstract}

Key words: stress, electroacupuncture, anxiety, elevated plus-maze, Fos-immunoreactivity.

\section{INTRODUCTION}

Acupuncture is a complex and ancient medical paradigm broadly known as "Chinese Traditional Medicine". Its original text, "Huang Di Nei Jing", dates from the V century b.C. (Beijing 1995).

Although the effect of acupuncture in specific points has been investigated, the mechanisms related to acupuncture effects are still not completely

Correspondence to: Regina Célia Spadari

E-mail: regina.spadari@unifesp.br understood. Usually, acupuncture points have a variety of clinical indications. For example, the point named PC6 (Nei guan) is indicated for the treatment of anxiety and the modulation of cardiac function (Liu 2004). Electroacupuncture (EEA) at PC6 has been reported to reduce activity in the hypothalamic arcuate nucleus (Zhong and $\mathrm{Li}$ 2009), the periaqueductal gray matter, the ventrolateral hypothalamus and the rostral ventrolateral medulla of rabbits ( $\mathrm{Fu}$ and Longhurst 2009, Tjen-A-Looi et al. 2009). PC6 stimulation 
also activated serotonergic neurons at the raphe nucleus (Moazzami et al. 2010). Moreover, the biochemical and behavioral reactions as well as the memory loss induced by mild chronic stress in rats were reduced by acupuncture at PC6 (Kim et al. 2009, 2011).

It is known that under certain circumstances stress may cause adverse consequences to the organic functions (Charmandari et al. 2005, Koolhaas et al. 2011) thus triggering the so-called stress-related diseases including anxiety, metabolic and endocrine disorders (Ortolani et al. 2011, 2014, Petrelluzzi et al. 2008, 2012), and cardiovascular diseases (Santos and Spadari-Bratfisch 2006). Whether acupuncture at PC6 would attenuate these stress effects has not yet been investigated.

The aim of this work was to investigate if eletroacupuncture at PC6 would modulate the stress-induced anxiety-like behavior and the level of activation of several brain areas. The guiding hypotheses was that the peripheral stimuli by electroacupuncture might modulate the activity of central components of the nervous system.

\section{MATERIALS AND METHODS}

\section{ANIMALS AND EXPERIMENTAL GROUPS}

Thirty-two male Wistar rats (Rattus novergicus) weighing 240 to $300 \mathrm{~g}$ were purchased from the "Centro de Desenvolvimento de Modelos Experimentais para Medicina e Biologia (CEDEME)" from the "Universidade Federal de São Paulo" (UNIFESP). The rats were housed in groups of four rats per cage in a temperature controlled room $\left(22 \pm 1^{\circ} \mathrm{C}\right)$, on a 12/12-h light/dark cycle (lights on at 7:00 a.m.), with free access to tap water and rodents chow (Labina, Purina, Sao Paulo, Brazil).

Rats were assigned to one of the following groups: unstressed (control), immobilization stress (IMMO), IMMO + electroacupuncture (EEA) at
PC6 (PC6) and IMMO + EEA at one point in the rat tail (TAIL).

All procedures were approved by the "Brazilian College of Animal Experimentation" and the "Institutional Committee for Ethics in Animal Experimentation" of the UNIFESP (certificate number 0093/12).

\section{IMMOBILIZATION STRESS (IMMO)}

Rats were submitted to immobilization stress for 60 minutes on three consecutive days, between 8:00 and 11:00 a.m. As shown in the Figure 1, the animals were kept in the supine position in a plastic cylinder provided with holes that allowed the externalization of the 4 members, head and tail. The rat's paws and tail were fixed with tape on the cylinder support. Forefeet remained supported dorsally, respecting the physiological range of motion and exposing the region where the PC6 point is located (Guimarães et al. 1997, Medeiros et al. 2003, Lee et al. 2004).

\section{ELECTROACUPUNCTURE (EEA)}

Disposable acupuncture $8 \mathrm{~mm}$ length and $0.18 \mathrm{~mm}$ diameter steel needles (Dongbang, Chungnam, Korea) were inserted $3 \mathrm{~mm}$ depth in PC6 or in the tail and connected to an electric stimulator (Sikuro DS $100 \mathrm{Jr}$ Rio de Janeiro, Brazil) that delivered alternate asymmetric pulses (positive rectangular and negative exponential) in a frequency of $3 \mathrm{~Hz}$ and intensity of $1 \mathrm{~mA}$ (Yang et al. 2002, Lee et al. 2004). Electric stimulation was done during the first $30 \mathrm{~min}$ of immobilization stress. Then, the needles were removed.

PC6 was located in each forehand paw of the rat, at one sixth of the distance between the center of the wrist flexion crease and the elbow flexion crease, and between the tendons of the long palmar muscle and the carpo radial flexor (Figure 1). Two "non-classical acupuncture points" were set in line, $0.5 \mathrm{~cm}$ distal from the base of the tail. Needles were 
inserted $3 \mathrm{~mm}$ deep, one at the level of the second coccygeal vertebra, and the other $2 \mathrm{~cm}$ distal, bordering the right and left ventral caudal nerves (Figure 1).

\section{ELEVATED PLUS-MAZE (EPM) TEST}

Immediately after the IMMO session, rats were placed individually in the center of the plus-maze at the junction between the open and the closed arms, facing one of the closed arms. The rat's behavior in the EPM was recorded during 5 min (Pellow et al. 1985, Melo and Brandão 1995, Ortolani et al. 2011, 2014).

The EPM was made of wood, and consisted of two open arms measuring $50 \times 10 \mathrm{~cm}$, crossed at a right angle with two opposed closed arms of the same size. These arms were enclosed by walls 40 $\mathrm{cm}$ high. The four arms delimited a central area of $10 \mathrm{~cm}^{2}$. The whole apparatus was elevated $50-\mathrm{cm}$ above the floor. To avoid falls, a rim of Plexiglas 1-cm high surrounded the open arms.

For each animal, the total number of entries in the closed arms of the maze, the percentage of open arm entries and the percentage of time spent on the open arms were calculated. Also, the total number of the following behavioral categories was computed: scanning (protruding the head over the edge of an open arm and scrutinizing in any direction), stretched-attend posture (the animal stretches to its full length with the forepaws, keeping the hind paws in the same place and turning back to the anterior position), end exploring (number of times the rat reached the end of an open arm), peeping out (stretching the head/shoulders from the closed arms to the central platform), grooming (cleaning any part of the body surface with the tongue, teeth and /or forepaws) and head dipping (dipping of the head below the level of the maze floor) were analyzed (Cruz et al. 1994, Albrechet-Souza et al. 2008). Unstressed rats were tested at the same time as IMMO rats.
Immediately after the behavioral test, the rats were anesthetized and perfused as described below. The behavioral tests did not interfere in the immunohistochemical analyzes, because the peak of the expression immunoreactivity Fos protein in response to a stimulus occurs in about 40 to $60 \mathrm{~min}$ (Cespedes et al. 2010, Le Sueur-Maluf et al. 2015).

FOS PROTEIN IMMUNOREACTIVITY (FOS-IR)

After the behavioral test, the rats were anesthetized with ketamine:xylazine 2:1 (1 mL/kg) and perfused with $100 \mathrm{~mL}$ of $0.9 \%$ saline for approximately 1 min, followed by $500-700 \mathrm{~mL}$ of $4 \%$ formaldehyde (from paraformaldehyde heated to $60-65^{\circ} \mathrm{C}$ ) and $\mathrm{H}_{2} \mathrm{O}$ at $4^{\circ} \mathrm{C}, \mathrm{pH} 9.5$, for approximately $25 \mathrm{~min}$.

The brains were post-fixed for $1 \mathrm{~h}$ in the same fixative solution, and then stored in a solution containing $20 \%$ sucrose for cryoprotection, at $4{ }^{\circ} \mathrm{C}$. Regularly spaced series $(5 \times 1$-in-5) of $30 \mu \mathrm{m}$-thick frozen sections were cut in the coronal plane, collected in ethylene glycol-based cryoprotectant solution and stored at $-20^{\circ} \mathrm{C}$ for later determination of Fos-ir. Fos-ir cells were identified using a polyclonal anti-serum raised in rabbits against synthetic human Fos (anti-Fos - 1:20,000; Oncogene, Cambridge, MA, USA). Immunohistochemistry was performed using a conventional avidin-biotin immunoperoxidase protocol (Hsu and Raine 1981) and Vectastain Elite reagents (Vector Laboratories, Burlingame, CA, USA). Tissues were pretreated with hydrogen peroxide (0.3\%; Sigma, St. Louis, MO, USA) before addition of the primary antibody to quench endogenous peroxidase activity in the tissue. The reaction with diaminobenzidine (DAB) $(0.05 \%$; Sigma) was amplified using nickel ammonium sulfate. The sections were then mounted on gelatincoated slides, allowed to dry for approximately $24 \mathrm{~h}$ and counterstained with $0.25 \%$ thionin for identification of the nervous tissue cytoarchitecture. Fos-ir cells in the sections were quantified under 
bright-field illumination using the Image-Pro Plus software (Media Cybernetics, Silver Spring, MD, USA).

The following areas were analyzed by Fos-ir: the prefrontal cortex (PFC); the medial $(\mathrm{MeA})$ and the central amygdala $(\mathrm{CeA})$; the paraventricular nucleus of the hypothalamus (PVN); the dorsomedial hypothalamic nucleus $(\mathrm{DMH})$; the lateral hypothalamus (LH); the dentate gyrus (DG); and the Cornus Ammon (CA1, CA2 and CA3) areas of the hippocampus. These areas were selected on the basis of previous evidence that they are involved in stress responses (UlrichLai and Herman 2009), and having as reference the following AP coordinates bregmas (Paxinos and Watson 2008): PFC: $+2.40 \mathrm{~mm}$; MeA: -2.76 $\mathrm{mm}$; CeA: $-2.92 \mathrm{~mm}$; PVN: $-1.56 \mathrm{~mm}$; DMH: -2.64 mm; DG and CA1, CA2 and CA3 areas of the hippocampus: $-2.76 \mathrm{~mm}$. The experimenter performing both the staining and the analysis was blind to the experimental conditions.

\section{STATISTICAL ANALYSIS}

Behavioral measurements and the number of Fos-ir neurons in each experimental group were analyzed by one way Analysis of Variance (ANOVA) followed by the Tukey test. Values of $p<0.05$ were considered significant.

\section{RESULTS}

EFFECT OF STRESS AND ELECTROACUPUNCTURE ON ANXIETY-LIKE BEHAVIORS

The results obtained in the EPM test are summarized in Table I. One way ANOVA showed no significant differences between IMMO and control groups regarding the following parameters: percentage of entries in the open arms $\left(\mathrm{F}_{(3,25)}=1.12 ; \mathrm{p}=0.36\right)$; number of entries in the closed arms $\left(\mathrm{F}_{(3,25)}=1.51\right.$; $\mathrm{p}=0.24)$; head dipping $\left(\mathrm{F}_{(3,25)}=1.22 ; \mathrm{p}=0.33\right)$; end arm exploring $\left(\mathrm{F}_{(3,25)}=1.23 ; \mathrm{p}=0.32\right)$; flatback approach $\left(\mathrm{F}_{(3,25)}=2.34 ; \mathrm{p}=0.10\right)$; or peeping out
$\left(\mathrm{F}_{(3,25)}=1.79 ; \mathrm{p}=0.18\right)$. Those parameters were not modified by EEA in PC6 or in the tail. Nevertheless, there were significant differences in the number of grooming $\left(\mathrm{F}_{(3,25)}=5.42 ; \mathrm{p}=0.02\right.$; one-way ANOVA $)$ and stretched-attend postures $\left(\mathrm{F}_{(3,25)}=2.59 ; \mathrm{p}=\right.$ 0.04). Moreover, the percentage of time spent in the open arms of the EPM showed a difference that is marginal to statistical significance $\left(\mathrm{F}_{(3,25)}=374.7\right.$; $\mathrm{p}=0.08)$. The increase in the number of grooming in the IMMO group was canceled by EEA in the tail or PC6. EEA also increased the percentage of time spent in the open arms of the EPM $(p<0.05)$. Furthermore, EEA did not modify the effect of IMMO on the number of stretched-attend postures and rearing.

FOS-IR

The quantitative analyses of Fos-ir in brain areas is summarized in Table II. IMMO group showed significant increase in Fos-ir in the following regions: PFC (Figure 2a); MeA (Figure 2b); $\mathrm{CeA}$ (Figure 2c); DG (Figure 2d); CA1, CA2 and CA3 areas of the hippocampus (Figure 2e and f), PVN (Figure 3a); LAT HYPO (Figure 3b) and DMH (Figure 3c). The activation of PFC, PVN, and DMH by IMMO was canceled by EEA at PC6 and attenuated by EEA in the tail (Table II; Figures 2a, $3 \mathrm{a}$ and $3 \mathrm{c}$, respectively). The activation of the other areas was canceled by EEA in PC6 or the tail (Table II; Figures 2 and 3).

\section{DISCUSSION}

The results presented here indicate that IMMO increased grooming and decreased stretched attend postures. Grooming is an important component of the rodent's behavioral repertoire (Berridge and Whishaw 1992, Kalueff and Tuohimaa 2005). It is sensitive to different kind of stressors (Spruijt et al. 1992) and it seems to play an important role in behavioral adaptation to stress, including stresscoping and arousal (Kalueff and Tuohimaa 2005). 
TABLE I

Behavior in the elevated plus-maze test of control rats and of rats submitted to immobilization (IMMO) and IMMO plus electroacupuncture at the tail or at PC6.

\begin{tabular}{|c|c|c|c|c|}
\hline Parameter & Control & IMMO & TAIL & PC6 \\
\hline $\begin{array}{l}\text { Time spent in the open } \\
\operatorname{arms}(\%)\end{array}$ & $26.35 \pm 4.34$ & $9.60 \pm 2.34^{*}$ & $27.19 \pm 6.09$ & $21.49 \pm 5.75$ \\
\hline $\begin{array}{l}\text { Entries in the open } \\
\text { arm }(\%)\end{array}$ & $34.15 \pm 3.76$ & $23.29 \pm 5.31$ & $35.66 \pm 6.31$ & $34.06 \pm 6.29$ \\
\hline $\begin{array}{l}\text { Entries in the closed } \\
\text { arms }\end{array}$ & $9.20 \pm 0.57$ & $7.85 \pm 1.05$ & $10.14 \pm 0.50$ & $8.66 \pm 0.98$ \\
\hline Grooming & $0.50 \pm 0.22$ & $2.42 \pm 0.71^{*}$ & $0.57 \pm 0.20$ & $1.16 \pm 0.30$ \\
\hline $\begin{array}{l}\text { Stretched attend } \\
\text { posture }\end{array}$ & $1.66 \pm 0.33$ & $2.14 \pm 0.34$ & $1.85 \pm 0.45$ & $0.66 \pm 0.21 * *$ \\
\hline Scanning & $7.00 \pm 0.51$ & $6.00 \pm 0.78$ & $7.00 \pm 1.09$ & $7.83 \pm 1.66$ \\
\hline Head dipping & $11.0 \pm 1.89$ & $7.71 \pm 1.10$ & $8.14 \pm 1.26$ & $10.50 \pm 1.74$ \\
\hline End arm exploration & $1.83 \pm 0.87$ & $0.42 \pm 0.29$ & $0.71 \pm 0.28$ & $1.16 \pm 0.65$ \\
\hline Flat back approach & $2.33 \pm 0.49$ & $1.71 \pm 0.28$ & $3.14 \pm 0.70$ & $1.16 \pm 0.65$ \\
\hline Peeping out & $8.66 \pm 0.76$ & $7.42 \pm 1.26$ & $5.85 \pm 0.79$ & $5.66 \pm 1.17$ \\
\hline
\end{tabular}

Values are means \pm SEM; $\mathrm{n}=7-8$ rats/group; ${ }^{*} \mathrm{p}<0.05$ as compared to control and tail groups; ** $<0.05$ as compared to IMMO group (one-way ANOVA and Tukey test).

TABLE II

Fos - immunoreactive cells (Fos-ir) in brain areas of control rats and rats submitted to immobilization (IMMO) and IMMO plus electroacupuncture at the tail or at PC6.

\begin{tabular}{|c|c|c|c|c|}
\hline Area & Control & IMMO & Tail & PC6 \\
\hline Paraventricular Nucleus (PVN) & $18.75 \pm 0.60$ & $228.25 \pm 31.36^{*}$ & $34.00 \pm 3.41$ & $16.00 \pm 1.61 * *$ \\
\hline Medial Amygdala (MeA) & $10.25 \pm 1.59$ & $171.50 \pm 21.24^{*}$ & $33.50 \pm 4.93$ & $17.75 \pm 2.57$ \\
\hline Central Amygdala (CeA) & $16.00 \pm 2.20$ & $134.50 \pm 19.71^{*}$ & $34.25 \pm 4.49$ & $20.50 \pm 2.80$ \\
\hline Dentate Gyrus (DG) & $6.75 \pm 1.33$ & $133.00 \pm 19.94 *$ & $23.33 \pm 2.13$ & $14.50 \pm 1.30$ \\
\hline Ammon Cornus 1 (CA1) & $1.00 \pm 0.406$ & $28.00 \pm 3.52 *$ & $2.00 \pm 0.35$ & $3.00 \pm 0.28$ \\
\hline Ammon Cornus 2 (CA2) & $1.00 \pm 0.28$ & $67.75 \pm 7.50^{*}$ & $6.00 \pm 1.06$ & $2.00 \pm 0.28$ \\
\hline Ammon Cornus 3 (CA3) & $1.00 \pm 0.40$ & $71.50 \pm 5.96^{*}$ & $5.00 \pm 1.61$ & $3.75 \pm 0.33$ \\
\hline Prefrontal Cortex (PFC) & $11.25 \pm 0.78$ & $209.00 \pm 19.45^{*}$ & $67.00 \pm 2.84$ & $19.50 \pm 0.93 * *$ \\
\hline $\begin{array}{l}\text { Dorsomedial Hypothalamus } \\
(\mathrm{DMH})\end{array}$ & $20.75 \pm 1.36$ & $119.25 \pm 15.91 *$ & $48.25 \pm 3.88$ & $26.75 \pm 1.16^{* *}$ \\
\hline $\begin{array}{l}\text { Lateral Hypothalamus } \\
\text { (LAT HYPO) }\end{array}$ & $10.50 \pm 1.42$ & $119.50 \pm 13.24^{*}$ & $30.50 \pm 3.00$ & $21.50 \pm 2.59$ \\
\hline
\end{tabular}

Values are means \pm sem of $7-9$ rats/group; ${ }^{*} \mathrm{p}<0.05$ as compared to control group, ${ }^{*}{ }^{*} \mathrm{p}<0.05$ as compared to tail group (one-way ANOVA and Tukey test). 


\section{$\mathbf{a}$}

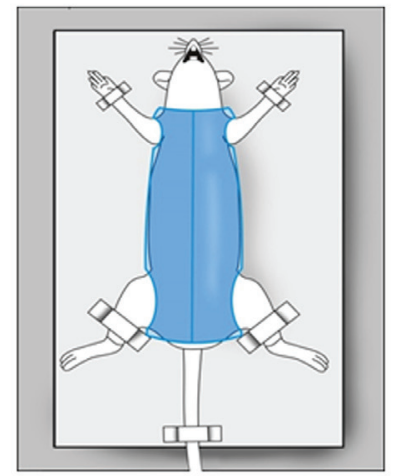

b
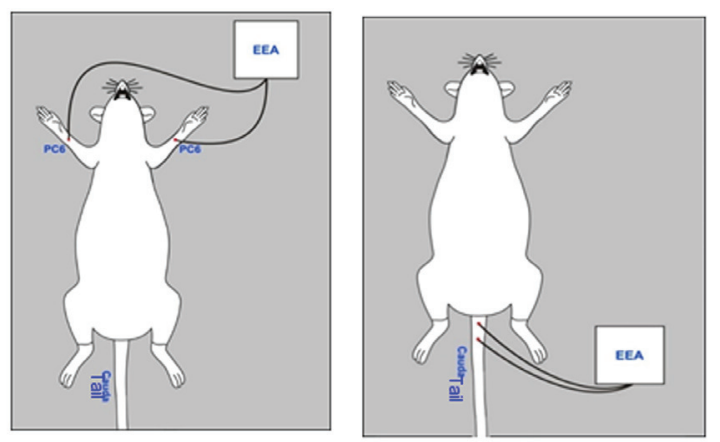

Figure 1 - (a) Schematic representation of immobilization and (b) of electroacunpucture in PC6 or (c) in the rat tail.

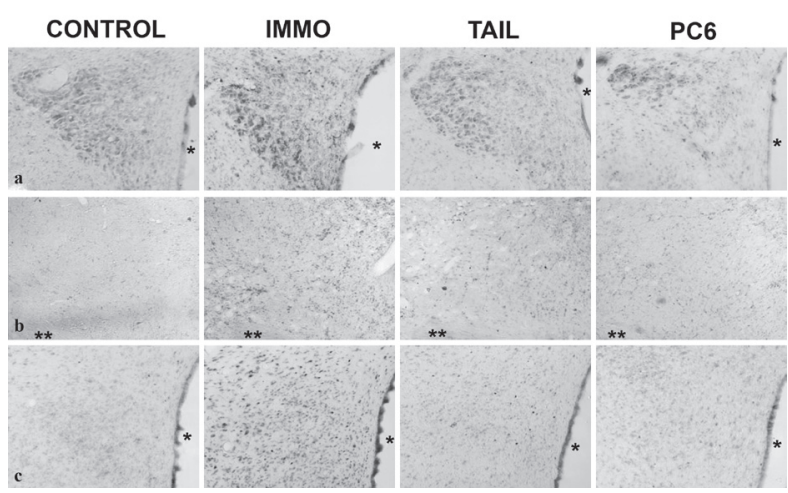

Figure 3 - Photomicrographs of coronal sections of rat brain regions with significant increases in Fos immunoreactive cells (dark spots) in rats submitted to immobilization stress (IMMO) as compared to control non-stressed rats (control) and the absence of activation in rats submitted to immobilization stress plus electroacunpucture in the tail or PC6. (a) paraventricular nucleus, (b) lateral hypothalamus, and (c) dorso medial hypothalamic nucleus. *indicates the third ventricle and **indicates the optic tract. Magnification, 200X.

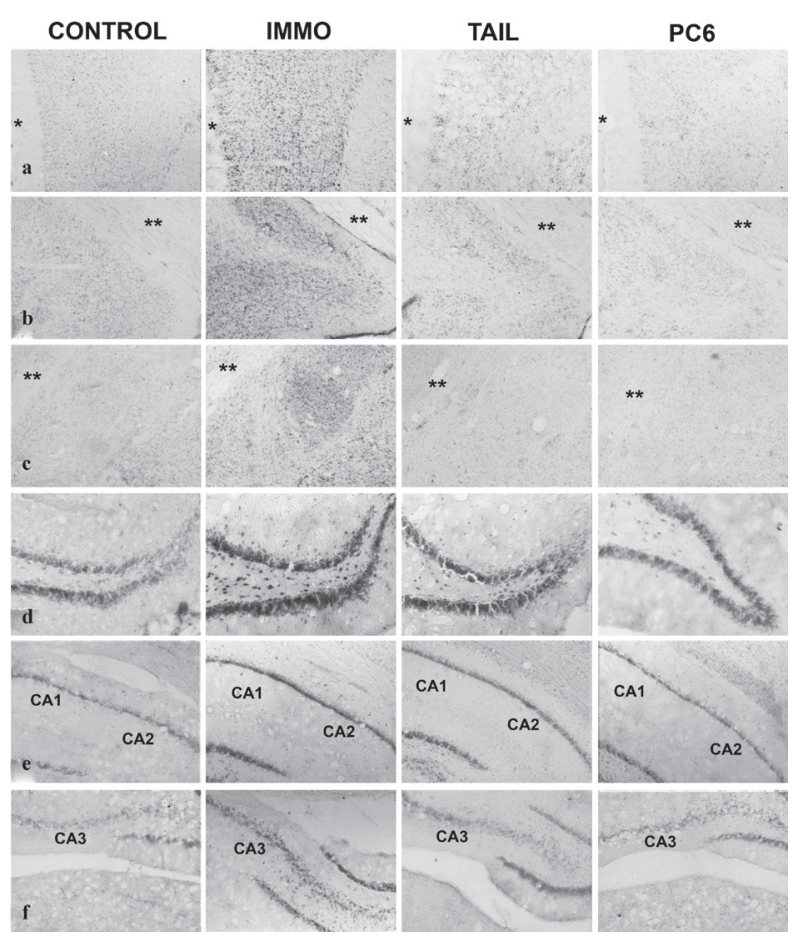

Figure 2 - Photomicrographs of coronal sections of rat brain regions with significant increases in Fos immunoreactive cells (dark spots) in rats submitted to immobilization stress (IMMO) as compared to control non-stressed rats (control) and the absence of activation in rats submitted to immobilization stress plus electroacunpucture in the tail or PC6. (a) prefrontal cortex, (b) medial amygdala, (c) central amygdala, (d) dentate gyrus, (e) CA1 and CA2, (f) CA3. *indicates the longitudinal brain fissure and **indicates the optic tract. Magnification, 200X.

Moreover, grooming is one of the main behavioral categories consistently altered by IMMO (Doremus-Fitzwater et al. 2009, Hennebelle et al. 2012). Reduction of grooming to control values occurred after EEA in the tail or PC6. A similar effect has been observed in rats submitted to IMMO and treated with omega-3 (Hennebelle et al. 2012). Aside from reducing grooming EEA increased the percentage of time spent in the open arms of the EPM. This parameter is a classical behavioral indicator of open space-induced anxiety (Pellow et al. 1985). Activity in the open arms reflects a conflict between the rodent's preference for protected areas (such as the ones presented by the walls of the closed arms) and their innate drive to 
explore novel environments (Walf and Frye 2007). Therefore, IMMO had a specific action altering some but not all the anxiety-like behaviors and EEA was specific as well, since it reduced the effect of IMMO on grooming, increased the time spent in the EPM open arms, and did not alter stretched attend posture. However, there was no difference between the effects of EEA applied to the rat tail or PC6.

Several brain areas modulate the stress induced anxiety-like behaviors (Bailey and Crawley 2009, Shoji and Mizoguchi 2010, Belzung et al. 2014). Indeed, IMMO had a significant effect on the lateral hypothalamus, that is related to the stressinduced increase in the heart rate (Deolindo et al. 2013). IMMO also enhanced Fos-ir in the DMH that has been pointed out as a potential therapeutic target for anti-anxiety drugs, since its inhibition reverses the cardiovascular alterations related to the state of anxiety (Sévoz-Couche et al. 2013). The amygdala activation also suggests that IMMO might induce anxiety and pathological fear (Le Doux and Damasio 2013, Hyman and Cohen 2013). Dysregulation of the interaction between the amygdala and the PFC may lead to fear and generalized anxiety (Duvarci and Pare 2014, Likhtik and Paz 2015, Raio and Phelps 2015) and may alter the role played by the hippocampus in fear conditioning (Rozeske et al. 2015). The activation by IMMO of those brain areas was attenuated or even canceled by EEA, either in PC6 or the rat tail.

Effects in brain areas related to the stress response of EEA applied in body segments other than PC6 have been previously demonstrated by others (Lee et al. 2004, Park et al. 2010, Yang et al. 2014). For example, stimulation of E36 activated the limbic system (Hui et al. 2005) and F3 caused limbic-cortical deactivation (Fang et al. 2007). Moreover, the HPA axis activity was altered by EEA (Xu et al. 2004, Li et al. 2014, Sun and Wang 2007, Zhu et al. 2015, Le et al. 2015). It has been suggested that the ability of one particular stimulus to modulate areas in the central nervous system depends on the kind of tissue in the accupoint region, usually muscular and conjunctive tissues (Hui et al. 2005, Fang et al. 2007), the presence of nervous fibers (Hui et al. 2007, 2009) and the stimulus type (Claunch et al. 2012)

The unexpected effect of EEA applied in the rat tail, at first considered as a "non-point", raises a discussion about the acupuncture specificity. It is important to mention that the designation of a "real acupuncture point" is empirical (Fang et al. 2009). Back in the XIX century, only 354 points were considered for clinical purposes, nowadays there are more than 2000 points, and the effect of a given point stimulation is unknown until it is tested. Hence, what is considered a non-point cannot be considered inert only because it has never been tested (Fang et al. 2009). So, data here presented have shown that the stimulated point in the rat tail is not inert. The tail region where needles were inserted has high density of afferent type I fibers (Mackenzie et al. 2015), and neurons are highly susceptible to electrical stimulation. This probably justify the attenuation of the effect of IMMO in the central nervous system. The absence of a control group submitted to acupuncture without electrical stimulation represents a limitation of this work.

However, some at least relative specificity of EEA in PC6 was observed. PC6 is classically described as being able to reduce anxiety, modulate humor states and improve cardiovascular function. All these actions are related to PVN, PFC and DMH. EEA at PC6 attenuated the IMMO activation of these areas and some anxiety-like behaviors more than EEA in the tail. Relative specificity of other acupuncture points was previously reported. The stimulation of F2, F3, or E44 produced deactivation of the amygdala, paralimbic structures, and the neocortex (Fang et al. 2009). Relative specificity was also reported by Claunch et al. (2012) for the stimulation of IG4, E36 e F3 and by Wang et al. 
(2015) who evaluated 33 classic points, including 24 points related to the activation of the PVN.

Concluding, the data presented herein suggested that the IMMO induced anxiety-like behavior was moderately attenuated by EEA in PC6 or the rat tail. EEA showed relative specificity concerning to the attenuation of the effects of IMMO in the central nervous system areas related to the stress response and anxiety.

\section{ACKNOWLEDGMENTS}

The authors acknowledge the financial support from the Coordenação de Aperfeiçoamento de Pessoal de Nível Superior (CAPES) and Fundação de Amparo à Pesquisa do Estado de São Paulo (FAPESP).

\section{REFERENCES}

ALBRECHET-SOUZA L, BORELLI KG AND BRANDÃO ML. 2008. Activity of the medial prefrontal cortex and amygdala underlies one-trial tolerance of rats in the elevated plus-maze. J Neurosci Methods 169(1): 109-118.

BAILEY RK AND CRAWLEY JN. 2009. Anxiety-related behaviors in mice. In: Methods of Behavior Analysis in Neuroscience, By Buccafusco JJ (Ed), CRC Press, $2^{\text {nd }}$ ed., New York, EUA.

BEIJING. 1995. State Administration of Traditional Chinese Medicine: Advanced Textbook on Traditional Chinese Medicine and Pharmacology 1: 21-30.

BELZUNG C, TURIAULT M AND GRIEBEL G. 2014. Optogenetics to study the circuits of fear - and depression - like behaviors: a critical analysis. Pharmacol Biochem Behav 122: 144-157.

BERRIDGE KC AND WHISHAW IQ. 1992. Cortex, striatum and cerebellum: control of serial order in a grooming sequence. Exp Brain Res 90(2): 275-290.

CESPEDES IC, DE OLIVEIRA AR, DA SILVA JM, DA SILVA AV, SITA LV AND BITTENCOURT JC. 2010. mRNA expression of corticotropin-releasing factor and urocortin 1 after restraint and foot shock together with alprazolam administration. Peptides 31(12): 2200-2208.

CHARMANDARI E, TSIGOS C AND CHROUSOS G. 2005. Endocrinology of the stress response. Annu Rev Physiol 67: 259-284.

CLAUNCH JD, CHAN ST, NIXON EE, QIU WQ, SPORKO T, DUNN JP, KUONG KK AND HUI KK. 2012. Commonality and specificity of acupuncture action at three acupoints as evidenced by fMRI. AM J Chin Med 40(4): 695-712.

CRUZ AP, FREI F AND GRAEFF FG. 1994. Ethopharmacological analysis of rat behavior on the elevated plus-maze. Pharmacol Biochem Behav 49(1): 171-176.

DEOLINDO MV, REIS DG, CRESTANI CC, TAVARES RF, RESSTEL LB AND CORRÊA FM. 2013. NMDA receptors in the lateral hypothalamus have a inhibitory influence on the tachycardiac response to acute restraint stress in rats. Eur J Neurosci 38(3): 2374-2381.

DOREMUS-FITZWATER TL, VARLINSKAYA EL AND SPEAR LP. 2009. Social and non-social anxiety in adolescent and adult rats after repeated restrain. Physiol Behav 97(3-4): 484-494.

DUVARCI S AND PARE D. 2014. Amygdala microcircuits controlling learned fear. Neuron 82(5): 866-880.

FANG J ET AL. 2009. The salient characteristics of the central effects of acupuncture needling: limbic - paralimbicneocortical network modulation. Hum Brain Mapp 30(4): 1196-1206.

FANG JL, NIXON E, LIU J AND HUI KK. 2007. The limbiccortical system and pain neuromatrix: Deactivation by acupuncture, activation by pain - an fMRI study at LV3. Abstract. Society for Neuroscience. Annual meeting in San Diego.

FU LW AND LONGHURST JC. 2009. Electroacupuncture modulates vIPAG release of GABA through presynaptic cannabinoid CB1 receptors. J Appl Physiol 106(6): 18001809.

GUIMARÃES CM, PINQE MC, YAMAMURA Y AND MELLO LE. 1997. Effects of acupuncture on behavioral, cardiovascular and hormonal responses in restraint stressed Wistar rats. Braz J Med Biol Res 30(12): 14451450.

HENNEBELLE M, BALASSE L, LATOUR A, CHAMPEILPOTOKAR G, DENIS S, LAVIALLE M, GISQUETVERRIER P, DENIS I AND VANCASSEL S. 2012. Influence of omega-3 fatty acid status on the way rats adapt to chronic restraint stress. PLoS ONE 7(7): e42142.

HSU SM AND RAINE L. 1981. Use of avidin-biotinperoxidase complex (ABC) in immunoperoxidase techniques: a comparison between $\mathrm{ABC}$ and unlabeled antibody procedures. J Histochem Cytochem 29: 577-580.

HUI KK, LIU J, MARINA O, NAPADOW V, HASELGROVE C, KWONG KK, KENNEDY DN AND MAKRIS N. 2005. The integrated response of the human cerebro-cerebellar and limbic systems to acupuncture stimulation at ST36 as evidenced by fMRI. Neuroimage 27(3): 479-496.

HUI KK ET AL. 2009. Acupuncture mobilizes the brain's default mode and its anti- correlated network in healthy subjects. Brain Res 1287: 84-103. 
HUI KK, NIXON EE, VANGEL MG, LIU J, MARINA O, NAPADOW V, HODGE SM, ROSEN BR, MAKRIS N AND KENNEDY DN. 2007. Characterization of the "dequi" response in acupuncture. BMC Complement Altern Med 7: 33.

HYMAN SE AND COHEN JD. Disorders of mood and anxiety. 2013. In: Principles of Neural Science, Kandel ER et al. (Eds), McGraw-Hill Companies, Inc., 1760 p.

KALUEFF AV AND TUOHIMAA P. 2005. Contrasting grooming phenotypes in three mouse strains markedly different in anxiety and activity (129S1, BALB/c and NMRI). Behav Brain Res 160(1): 1-10.

KIM H, PARK HJ, HAM SM, HAHM DH, LEE HJ, KIM KS AND SHIM I. 2009. The effects of acupuncture stimulation at PC6 (Neiguan) on chronic mild stressinduced biochemical and behavioral responses. Neurosci Lett 460(1): 56-60.

KIM H, PARK HJ, SHIM HS, HAN SM AND HAHM DH. 2011. The effects of acupuncture (PC6) on chronic mild stress-induced memory loss. Neurosci Lett 488(3): 225228.

KOOLHAAS JM ET AL. 2011. Stress revisited: A critical evaluation of the stress concept. Neurotic Beh Rev 35: 1291-1301.

LE DOUX JE AND DAMASIO AR. 2013. Emotions and feelings. In: Principles of Neural Science, Kandel ER et al. (Eds), McGraw-Hill Companies, Inc., 1760 p.

LE SUEUR-MALUF L, VIANA MB, NAGAOKA MR, AMORIM AL, CARDOSO AN, RODRIGUES BC, MENDES NF, BITTENCOURT JC AND CESPEDES IC. 2015. Behavioral alterations and Fos protein immunoreactivity in brain regions of bile duct-ligated cirrhotic rats. An Acad Bras Cienc 87: 331-341.

LEE HJ, LEE B, CHOI SH, HAHM DH, KIM MR, ROH PU, PYUN KH, GOLDEN G, YANQ CH AND SHIM I. 2004. Electroacupuncture reduces stress-induced expression of c-fos in the brain of the rat. Am J Chin Med 32(5): 795796.

LI Q, YUE N, LIU SB, WANG ZF, MI WL, JIANG JW, WU GC, YU J AND WANG YQ. 2014. Effects of chronic acupuncture on depression-and anxiety- like behaviors in rats with chronic neurophatic pain. Evid Based Complement Alternat Med 14: 1-10.

LIKHTIK E AND PAZ R. 2015. Amygdala-prefrontal interations in (mal) adaptative learning. Trends Neurosci 38(3): 158-166.

LIU G. 2004. Tratado Contemporâneo de Acupuntura e Moxibustão: Pontos e Meridianos. São Paulo: Roca, 149 p. MACKENZIE SJ, YI JL, SINGLA A, RUSSELL TM AND

CALANCIE B. 2015. Innervation and function of the rat tail muscles for modeling cauda equina injury and repair. Muscle Nerve: 52(1) 94-102.
MEDEIROS MA, CANTERAS NS, SUCHECKI D AND MELLO LE. 2003. Analgesia and C - Fos expression in periaqueductal Gray induced by electroacupuncture at the zusanli point in rats. Brain Res 973(2): 196-204.

MELO LLAND BRANDÃO ML. 1995. Involvement of 5- HT (1A) and 5- HT (2) receptors of the inferior colliculus in aversive states induced by exposure of rats to the elevated plus - maze test. Behav Pharmacol 6(4): 413-417.

MOAZZAMI A, TJEN-A-LOOI SC, GUO ZL AND LONGHURST JC. 2010. Serotonergic projection from nucleus raphe pallidus to rostral ventrolateral medulla modulates cardiovascular reflex responses during acupuncture. J Appl Physiol 108(5): 1336-1346.

ORTOLANI D, GARCIA MC, MELO-THOMAS L AND SPADARI-BRATFISCH RC. 2014. Stress - induced endocrine response and anxiety: the effects of comfort food in rats. Stress 17(3): 211-218.

ORTOLANI D, OYAMA LM, FERRARI EM, MELO LL AND SPADARI-BRATFISCH RC. 2011. Effects of comfort food on food intake, anxiety-like behavior and the stress response in rats. Physiol Behav 103(5): 487-492.

PARK HJ, KIM HY, HAHM DH, LEE H, KIM KS AND SHIM I. 2010. Electroacupuncture to ST36 ameliorates behavioral and biochemical responses to restraint stress in rats. Neurol Res 1: 111-115.

PAXINOS G AND WATSON C. 2008. The Rat Brain in Stereotaxic Coordinates. $6^{\text {th }}$ ed., Compact. Elsevier AP.

PELLOW S, CHOPIN P, FILE SE AND BRILEY M. 1985. Validation of open: Closed arm entries in an elevated plusmaze as a measure of anxiety in the rat. J Neurosc Meth 14: 149-167.

PETRELLUZZI KFS, GARCIA MC, PETTA CA, GRASSIKASSISSE DM AND SPADARI-BRATFISCH RC. 2008. Salivary cortisol concentrations, stress and quality of life in women with endometriosis and chronic pelvic pain. Stress 11(5): 390-397.

PETRELLUZZI KFS, GARCIAMC, PETTACA, MONTEIRO NRO, CESPEDES IC AND SPADARI-BRATFISCH RC. 2012. Physical therapy and psychological intervention normalize cortisol levels and improve vitality in women with endometriosis. J Psych Obst Gynecol 33(4): 22-36.

RAIO CM AND PHELPS EA. 2015. The influence of acute stress on the regulation of conditioned fear. Neurobiol Stress 1: 134-146.

ROZESKE RR, VALERIO S, CHAUDUN F AND HERRY C. 2015. Prefrontal neuronal circuits of contextual fear conditioning. Genes Brain Behav 14(1): 22-36.

SANTOS IN AND SPADARI-BRATFISCH RC. 2006. Stress and cardiac beta adrenoceptors. Stress 9(2): 69-84.

SÉVOZ-COUCHE C, BROUILLARD C, CAMUS F, LAUDE D, DE BOER SF, BECKER C AND BENOLIEL JJ. 2013. Involvement of the dorsomedial hypothalamus and the nucleus tractus solitarii in chronic cardiovascular changes 
associated with anxiety in rats. J Physiol 591(Pt7): 18711887.

SHOJI H AND MIZOGUCHI K. 2010. Acute and repeated stress differentially regulates behavioral, endocrine, neural parameters relevant to emotional and stress response in young and aged rats. Behav Brain Res 211(2): 169-177.

SPRUIJT BM, HOL T AND ROUSSEAU J. 1992. Approach, avoidance, and contact behavior of individually recognized animals automatically quantified with an imaging technique. Physiol Behav 51(4): 747-752.

SUN DW AND WANG L. 2007. Influence of acupuncture on HPAA in a rat model of chronic stress-induced depression. Shanghai J Acupuncture Moxibustion 26: 32-34.

TJEN-A-LOOI SC, LI P AND LONGHURST JC. 2009. Processing cardiovascular information in the vIPAG during electroacupuncture in rats: roles of endocannabinoids and GABA. J Appl Physiol 106(6): 1793-1799.

ULRICH-LAI YM AND HERMAN JP. 2009. Neural regulation of endocrine and autonomic stress responses. Nat Rev Neurosc 10: 397-409.

WALF AAAND FRYE CA. 2007. The use of the elevated plus maze as an assay of anxiety-related behavior in rodents. Nat Protoc 2(2): 322-328.

WANG SJ, ZHANG JJ, YANG HY, WANG F AND LI ST. 2015. Acupoint specificity on acupuncture regulation of hypothalamic - pituitary- adrenal cortex axis function. BMC Complement Altern Med 15: 87.

XU H, SUN ZR AND LI LP. 2004. Effects of acupuncture on the hypothalamus-pituitary-adrenal axis in the patient depression. Chin Acupuncture Moxibustion 24: 78-80.

YANG CH, LEE BB, JUNG HS, SHIM I, ROH PU AND GOLDEN GT. 2002. Effect of electroacupuncture on response to immobilization stress. Pharmacol Biochem Behav 72(4): 847-855.

YANG L, YUE N, ZHU X, HAN Q, LI B, LIU Q, WU G AND YU J. 2014. Electroacupuncture promotes proliferation of amplifying neural progenitors and preserves quiescent neural progenitors from apoptosis to alleviate depressivelike and anxiety-like behaviors. Evid Based Complement Alternat Med 2014: 872568.

ZHONG H AND LI GZ. 2009. Study of mechanism of electroacupuncture of "Neiguan" (PC6) in inhibiting ventricular arrhythmia induced by hypothalamic electrostimulation in the rabbit. Zhen Ci Yan Jiu 34(1): 43-47.

ZHU J, CHEN Z, ZU L, MENG Z, WU G AND TIAN Z. 2015. Arginine vasopressin and arginine vasopressin receptor $1 \mathrm{~b}$ involved in electroacupuncture- attenuated hypothalamicpituitary- adrenal axis hyperactivity in hepatectomy rats. Neuromodulation 19(5): 498-506. 